\title{
A CENTRALIDADE DO TRABALHO NA ANÁLISE GEOGRÁFICA
}

\author{
Work: a central category of geographic analysis
}

\section{Trabajo: una categoría central de análisis geográfico}

Verônica Ferraz de Oliveira ${ }^{1}$ https://orcid.org/0000-0001-6031-9441 Ana Emília de Quadros Ferraz ${ }^{2}$ https://orcid.org/0000-0002-0137-3787

\footnotetext{
${ }^{1}$ Doutorado e Mestrado em Geografia pela Universidade Federal de Sergipe. Graduação em Geografia pela Universidade Estadual do Sudoeste da Bahia - UESB. Veronica.ferraz@ gmail.com - Atuação profissional: Faculdade Independente do Nordeste - FAINOR- Brasil

${ }^{2}$ Pós-doutorado e Doutorado em Geografia pela Universidade Federal de Sergipe -Brasil; Mestrado em Ciências Sociais pela PUC -SP. Graduação em Geografia pela Universidade Estadual do Sudoeste da Bahia - UESB. milaferraz@gmail.com - Atuação profissional: Universidade Estadual do Sudoeste da Bahia - UESB
}

Recebido em: 04/05/2019

Aceito para publicação em: 19/06/2019

\section{Resumo}

Este artigo tem o objetivo de analisar a categoria trabalho porque ele é um fenômeno inerente ao homem e, por isso, não pode escapar dos estudos científicos e, sobretudo, geográficos. Para diversas ciências as atividades laborativas produzem elementos que atendem as necessidades humanas, mas os geógrafos complementam que o trabalho vai para além deste fenômeno, pois ele, também, é elemento primordial na produção do espaço. Portanto, o trabalho tem sido instrumento para que a Geografia se aproprie do tema e faça dele uma categoria central das análises geográficas. Esse é um tema que carrega determinadas nuances de cada momento histórico. Trata-se de um assunto do âmbito não somente técnico, mas, sobretudo, social, que o torna amplo, rico e inesgotável.

Palavras chave: Homem, Trabalho, Análise Geográfica

\begin{abstract}
The aim of this article is to analyze the work category; as work is a phenomenon inherent to the mankind, and therefore cannot evade scientific studies, especially the geographic studies. The labor activities meet the human needs, and are studied in different perspectives by different sciences. Geographers complement this knowledge, when affirming that the work goes beyond this phenomenon, as it is as well a primordial element in the production space. Therefore, the work is a tool to Geography, making the subject one of the central categories of the Geographical analyzes. This subject brings certain nuances from each historical moment, and its context is not purely technical, but, overall social, what makes it broad, rich and inexhaustible.
\end{abstract}

Keywords: Man, Work, Geographic Analysis

\section{Resumen}


Este artículo pretende analizar la categoría de trabajo porque es un fenómeno inherente al hombre y, por lo tanto, no puede escapar de los estudios científicos y, sobre todo, de los estudios geográficos. Para las diferentes ciencias, las actividades laborales producen elementos que satisfacen las necesidades humanas, pero los geógrafos complementan que el trabajo va más allá de este fenómeno, ya que también es un elemento primordial en la producción del espacio. Por lo tanto, el trabajo ha sido fundamental para permitir que la Geografía se apropie del tema y lo convierta en una categoría central de análisis geográfico. Este es un tema que lleva ciertos matices de cada momento histórico. Es una cuestión no solo técnica, sino sobre todo social, que la hace amplia, rica e inagotable.

Palabras clave: Hombre, Trabajo, Análisis Geográfico.

\section{Introdução}

O trabalho tem sido objeto de análises e investigações em todos os âmbitos das ciências sociais, políticas e humanas. A Sociologia, a Antropologia, a Economia, a História, dentre outras áreas, tem estudado a categoria trabalho, detalhadamente e com afinco, pois é um fenômeno inerente ao homem e, por isso, não pode escapar dos estudos científicos e, sobretudo, geográficos.

Conforme Marx (2013), as atividades laborativas exercidas pelos homens, além de produzir elementos que atendem às suas necessidades, produzem a si mesmos. Vale destacar que os geógrafos complementam que, além disso, o trabalho produz, também, o espaço. A produção do espaço do qual o trabalho, permite o homem realizar, tem sido instrumento para que a Geografia se aproprie do tema e faça análises apuradas desse fenômeno. Assim sendo, alguns questionamentos podem ser feitos para enriquecimento dos estudos, tais como: qual a relação do trabalho com a Geografia? O que tem a ver o trabalho com a produção do espaço? Até que ponto o trabalho é uma categoria geográfica central?

Ao empreender uma análise da evolução do pensamento geográfico, percebe-se que a categoria trabalho foi inserida em sua estrutura teórica, primeiro, por Vidal de La Blache (1954) e, posteriormente, por Pierre George $(1979,1988)$. O primeiro enfoca o trabalho como interlocutor entre homem-natureza, pois é por meio dele que o homem garante as condições e os meios de sobrevivência. E o segundo vincula as atividades laborativas à dimensão do emprego.

\section{Trabalho: uma categoria central de análise geográfica}


A abordagem do trabalho como "categoria central" na Geografia é um fato relativamente recente, visto que, por muito tempo, o discurso acerca dele, nesse ramo da ciência, teve posição de mediador e não um lugar central como apresenta hodiernamente. Dessa maneira, Thomáz Júnior assevera:

Se pudéssemos traçar uma linha na história, o trabalho na Geografia, invariavelmente, esteve (des)sintonizado da sociedade (enquanto parte do processo social movido pela fúria reprodutiva do capital ancorada na extração de mais-valia e da vinculação do trabalho abstrato ao empreendimento societário reinante), portanto distante do pacto de classes que a burguesia orquestrou para consolidar seu projeto de dominação. Fora também da natureza, enquanto elemento distante do corpus natural e visto somente como atividades humanas, já que o homem já estava fora da natureza (THOMAZ JÚNIOR, 2002, p. 4).

Thomáz Júnior (2002) convida seus leitores a compreender o trabalho em sua totalidade social. Para isto, ele os leva a refletir acerca do processo dialético que unifica as dimensões ambientais e socioespaciais, tendo o trabalho como elemento que se vincula a essas duas dimensões. Nesse sentido, a Geografia apresenta-se com o intuito de resgatar a ontologia do trabalho e, dessa maneira, colocá-lo como categoria central de análise dos fenômenos de alguns ramos dessa ciência. Como assevera o autor: ontologicamente, o trabalho, em todas as suas dimensões, é a base fundante do autodesenvolvimento da vida material e espiritual (THOMÁZ JÚNIOR, 2002).

Neste sentido, entende-se o trabalho como uma categoria geográfica, porque ele possibilita que o homem modifique a natureza e a si mesmo, além de permitir-lhe o ato de produzir o espaço. Ou seja, ele tem uma importante e imprescindível função nos processos metabólicos entre o ser social e o meio natural. Segundo Thomáz Junior (2002), o trabalho, na condição de fonte primária da articulação entre a causalidade e teleologia, é um processo entre atividade humana e natureza, que se sintetiza na célula do ser social. Thomáz Junior comunga esse pensamento com Antunes (2006), o qual salienta:

O trabalho é, portanto, resultado de um pôr teleológico que (previamente) o ser social tem ideado em sua consciência, fenômeno este que não está essencialmente presente no ser biológico dos animais. [...] a categoria ontologicamente central, presente no processo de trabalho, é anunciada: através do trabalho, uma posição teleológica é realizada no interior do seu material, como nascimento de uma nova objetividade. A primeira consequência disso é que o trabalho torna-se protoforma de toda a práxis social (ANTUNES, 2006, p. 136). 
Dessa forma, entende-se que o trabalho é que assegura a existência humana, promove a vida e possibilita a autorrealização dos homens. Segundo Antunes (2006), nesse processo de autorrealização da humanidade, de avanço do ser em relação ao seu agir instintivo, bem como do seu avanço em relação à natureza, configura-se o trabalho como referencial ontológico fundante de práxis social. Nesse sentido, é possível afirmar que o labor exerce um papel fundamental para a existência do ser social e, sobretudo, para a produção do espaço. Assim, para Thomáz Júnior:

[...] o conteúdo do metabolismo social do capital que faz com que sociedade e natureza e, as mediações que governam essa relação dialética, sejam "lidas" pela Geografia como base fundante da compreensão da polissemia do trabalho no mundo atual ou a polissemização da classe-que-vive-do-trabalho (THOMAZ JÚNIOR, 2002, p. 4-5, destaque do autor).

Mediante tais análises acerca da categoria trabalho, surge uma preocupação em relação à sua existência, por isso considera-se temerária a tese do "Fim do Trabalho". Estudos acerca desse tema mostram resultados que reforçam a sua importância para a vida da humanidade. Sendo assim, pode-se afirmar que é ilegítima a possibilidade de um dia o trabalho deixar de existir. Ao partir desta ideia, cabe questionar: até que ponto o homem consegue suprir suas necessidades e realizar-se sem o trabalho? De que maneira o capital poderia se manter sem o trabalho como um dos instrumentos de sua exploração? É quase impossível não afirmar que o trabalho é a base fundante da vida humana e é exatamente por isso que é imprescindível à sua sobrevivência. Conforme Thomáz Júnior:

Efetivamente o que se vê não é o fim do trabalho, mas sim a continuação desmedida da exploração do trabalho, sob novas exigências da lei do valor e uma nova gestão societal gerida por novos referenciais, impulsionados e sacramentados no interior do processo de reestruturação produtiva do capital que tem feito com que os trabalhadores vivam estágios de subproletarização diversificada (THOMÁZ JÚNIOR, 2002, p. 11).

É de suma importância esclarecer que a discussão exposta aqui, acerca do trabalho, não se limita ao "simples emprego". Sabe-se que as atividades laborativas realizadas pelo homem vão além daquelas que lhes são remuneradas, pois, mesmo que ele esteja desempregado, faz trabalho em sua casa e no meio em que vive, para garantir sua sobrevivência. Nesse sentido, Thomáz Júnior (2002) afirma que é preciso considerar 
o universo plural do mundo do trabalho, por isso o que está moribundo é o emprego e não o trabalho. Ademais, é preciso compreender:

O mundo do trabalho não se restringe mais à fábrica, tampouco a fábrica é o mundo do trabalho; o trabalho tem seu sentido ampliado, revelando-se polissêmico. Em tempos de globalização outros códigos e arranjos espaciais se apresentam para serem decifrados (THOMAZ JÚNIOR, 2002, p. 9).

Ao realizar análises sobre o trabalho, Francescone defende que tanto o desemprego quanto a precarização do trabalho tem levado a uma reorganização, com o objetivo de evitar o seu desaparecimento. De acordo com o autor:

No mundo do trabalho as evidências desse processo de reorganização consistem no aumento do desemprego estrutural e na precarização do trabalho. O desemprego estrutural responde à utilização das inovações tecnológicas e reestruturação organizacional e produtiva enquanto a precarização do trabalho recebe o nome de flexibilização do trabalho (FRANCESCONI, 2007, p. 4).

Os apontamentos explicitados, até o momento, levam ao entendimento de que o trabalho pode determinar ou redefinir o processo social e a produção do espaço geográfico. Daí o seu caráter de relevância como uma das categorias de análise do espaço. Atualmente, a Geografia do trabalho possui bases sólidas para utilizá-lo em seus estudos e análises acerca do mundo e da realidade em que se vive.

Há estudos que permitem entender que a produção do espaço é determinada pelo tipo de trabalho realizado nele, mesmo que tenha vínculo ou não com a produção ou reprodução do capital. O exemplo que pode ser citado para comprovar a relação do tipo de trabalho com a produção do espaço é a Divisão Territorial do Trabalho, que define a produção de lugares diferenciados, revelando as particularidades de cada dimensão espacial.

Portanto, conforme Oliveira (2009), a Geografia deve analisar o trabalho para além do controle que o capital tenta manter sobre ele. Isto pode ser perfeitamente observado no momento em que uma pessoa prepara seus alimentos, realiza atividades cotidianas em sua casa, uma vez que por esse tipo de trabalho ela não possui remuneração e tampouco essa atividade gera capital. Daí conclui-se que o capital se apropria do trabalho, mas nem sempre o trabalho se subordina a ele. $\mathrm{O}$ trabalhador do campo, por exemplo, pode realizar atividade laborativa que produza capital, mas 
também realiza atividades como o cultivo de uma horta ou o desenvolvimento de uma roça que sirva apenas para o sustento familiar. Diante disso, observa-se que as afirmações de Thomaz Júnior são uma realidade. Na verdade, o que tem sofrido riscos é muito mais o emprego do que propriamente o trabalho em si.

Para Thomaz Júnior (2005, p. 3), o exercício do controle social do capital e do Estado sobre o trabalho é um tema permanentemente ligado à pesquisa geográfica. Ele expõe que o trabalho assume, no âmbito do metabolismo do capital, uma constante (re)arrumação territorial que tem na territorialização as evidências para o entendimento do que se passa da formalidade, atingindo o tecido social e, principalmente, os trabalhadores, as formas de contratação, de remuneração, de representação e de organização política.

Vê-se, então, que as questões aqui levantadas atestam que o trabalho exerce o papel de centralidade na Geografia, pois:

[...] não há discussão do trabalho sem discussão do sujeito. Assim, sob o ponto de vista da sociedade do capital, o sujeito deve estar na esfera do trabalho. Por isso as metamorfoses pelas quais o trabalho tem passado, atingem em cheio a dinâmica espacial do ser que trabalha, redimensionando a configuração geográfica da territorialização, da desterritorialização e da reterritorialização do trabalho em suas diferentes formas de expressão (THOMAZ JÚNIOR, 2002, p. 13).

Santos (1980) sugere que o espaço deve ser considerado um fato social, um produto da ação humana, uma natureza socializada, pois é através do seu trabalho de cunho produtivo e social que o homem, como sujeito da história, vai construindo o espaço. É sob esta ótica de relação sociedade-trabalho-natureza que a Geografia se pauta e se fundamenta para adotar o trabalho como sua categoria de análise central. São estas e outras contribuições teóricas que orientam as análises e aproximam o trabalho da Geografia, fornecendo meios para que essa ciência o tenha como categoria importante que subsidia estudos e análises do espaço.

\section{Trabalho: conceitos e concepções}

O trabalho nem sempre teve a mesma importância e o mesmo valor. O seu significado tem assumido papéis diferentes no decorrer dos tempos. A palavra trabalho é derivada do latim, tripliare, advinda de tripalium, nome dado a um instrumento de tortura muito utilizado para martirizar pessoas e, também, para manter preso o animal 
difícil de ser contido. Portanto, em determinados momentos da História, ele se identifica com tortura, labuta, sofrimento, pena e algo que provoca desprazer, estando ligado a uma visão negativa. Segundo Vatin:

Tornou-se banal recordar que o termo trabalho provém do latim tripalium, que designa um instrumento de tortura. Mas isto é apenas uma meia verdade, pois o tripalium é, em primeiro lugar, um banal tripé (instrumento de três pés), que pode, é certo, servir de apoio (no sentido próprio e figurado) à tortura, mas também, e em primeiro lugar, conter grandes animais quando lhes são prestados cuidados ou colocadas ferramentas. [...] foi através do verbo (tripaliere: fazer sofrer no tripalium) que surgiu o significado moderno de punição (VATIN, 1999, p. 15, destaque do autor).

Grint corrobora a ideia de Vatin, acerca do conceito de trabalho, como uma atividade relacionada com dor, aflição e ausência de liberdade. Para ele:

[...] Até o século XVI duas palavras diziam respeito a trabalho: oevrer, era um trabalho de arte, mas derivava do latim operarus que significava um homem de dor ou de aflição; enquanto labourer, lavrar vinha do latim labor ou faina agrícola. Estas duas palavras tendiam a ser substituídas pela única palavra travailler, trabalhar, do latim tripaliare que significa torturar usando um tripalium um garfo com três dentes (GRINT, 1998, p. 27-28, destaque do autor).

$\mathrm{Na}$ antiguidade, tanto na cultura grega quanto na romana, o trabalho manual era desvalorizado, sendo, em sua maior parte, uma atribuição exclusiva de escravos. Para os homens livres, eram destinadas as atividades relacionadas à intelectualidade, isto é, ao mundo das ideias. Esta visão acerca do trabalho perdura na Idade Média. Somente na Idade Moderna, por volta do século XIX, esta concepção começa a se alterar.

Assim, Hegel (2008) considera o trabalho como condição de liberdade; Marx (2013), apesar de criticar a visão otimista Hegeliana, não desmerece a condição libertadora que o trabalho possui. Para Hegel (2008), o valor do trabalho não é dado apenas por ele possibilitar que o homem satisfaça suas necessidades, mas pela capacidade de "formar o homem", tornando-o capaz de transformar a realidade e participar, efetivamente, da vida em sociedade.

Marx (2013) acolhe a ideia de Hegel de que o homem é o resultado do seu próprio trabalho, mas o critica, porque, para ele, Hegel só concebe o trabalho em seu aspecto positivo e só reconhece as atividades do espírito e do intelecto. Destaca-se que a filosofia Marxiana tem como categoria central o trabalho humano como atividade 
prática em seu intercâmbio com a natureza. De acordo com Marx (2013), é a atividade prático-sensível do homem que possibilita sua autoconstrução, por isso ele concebe a Filosofia da Práxis.

Segundo Marx (2013), o trabalho é, antes de tudo, um processo entre o homem e a natureza, processo este em que o homem, por sua própria ação, medeia, regula e controla seu metabolismo com a natureza. Isto significa que ele a altera, por meio do trabalho, para suprir as suas necessidades e garantir a sua sobrevivência. Marx (2013) ainda acrescenta que o homem, ao agir sobre a natureza externa, modifica-a e, ao mesmo tempo, transforma sua própria natureza.

Existem concepções simplistas que nos levam a pensar que não há diferença entre o trabalho humano e o de um animal, como a formiga, a abelha, a aranha, o castor, o joão de barro e outros, pois todos praticam esta ação. No entanto, Marx (2013) afirma que no final do processo de trabalho efetuado pelo homem chega-se a um resultado que já estava presente na representação do trabalhador no início do processo, portanto, um resultado que já existia idealmente. Houve um planejamento, um objetivo e uma intenção. Para ele, a diferença entre o trabalho do animal e o do homem é que o homem tem um propósito consciente na concretização do trabalho (MARX, 2013). Braverman (1980) corrobora este pensamento ao afirmar que o trabalho humano é consciente e proposital, ao passo que no caso dos outros animais é instintivo.

Segundo Harvey (2013), Marx confere ao processo de trabalho um sentido não apenas da criatividade, mas também de nobreza. Ele acredita que o pensador, ao conceber as ideias acerca desse tema, foi influenciado pelo Romantismo do início do século XIX, pois seus primeiros escritos transpiram sentimentos e significados românticos. Harvey (2013) faz esta afirmação com base no próprio Marx: Os seres humanos podem transformar radicalmente o mundo, de acordo com sua imaginação e com determinado propósito, e ter consciência do que estão fazendo. Com isso, têm o poder de transformar a si mesmos.

Harvey (2013) chama atenção para a responsabilidade que Marx confere quando leva o homem a refletir sobre os propósitos humanos. Ele sublinha que se deve tomar consciência de como e quando intervir no mundo, realizando a transformação da natureza humana. E ainda afirma: não há uma transformação neutra de uma natureza exterior à nossa. O que fazemos "lá fora" tem muito a ver conosco "aqui dentro".

Marx (2008) elabora várias reflexões acerca das atividades laborativas do homem, dentre elas está o questionamento sobre a geração de riqueza para os donos dos 
meios de produção, ao passo que empobrece o trabalhador. Ele nos faz refletir sobre esse paradoxo do trabalho: a produção de riqueza de poucos e miséria de muitos. Conforme o teórico,

\begin{abstract}
O trabalhador se torna tanto mais pobre quanto mais riqueza produz, quanto mais a sua produção aumenta em poder e extensão. $\mathrm{O}$ trabalhador se torna uma mercadoria tão mais barata quanto mais mercadoria cria. Com a valorização do mundo das coisas (Sündenfall) aumenta em proporção direta a desvalorização do mundo dos homens (Menschenwelt). $\mathrm{O}$ trabalho não produz somente mercadorias; ele produz a si mesmo e ao trabalhador como uma mercadoria, e isto na medida em que produz, de fato, mercadorias em geral (MARX, 2008, p. 80, destaque do autor).
\end{abstract}

Ao realizar análises acerca do labor, Marx promove a efetivação de várias reflexões, tais como: trabalho alienado, trabalho concreto/útil/vivo e abstrato/morto. Dentro das reflexões expostas acerca das atividades laborativas, ele se remete ao fato de que o fruto da atividade produtiva do operário é a mercadoria, e esta é propriedade de outrem. Ou seja, o trabalhador não é dono do seu trabalho, tampouco do que ele produz com seu labor. Para esse fenômeno, o teórico assim define como trabalho alienado ou estranhamento do trabalho:

Esta relação é a relação do trabalhador com a sua própria atividade como uma [atividade] estranha não pertencente a ele, a atividade como miséria, a força como impotência, a procriação como castração. A energia espiritual e física própria do trabalhador, a sua atividade pessoal - pois o que é a vida senão atividade - como uma atividade voltada contra ele mesmo, independente dele, não pertencente a ele. $\mathrm{O}$ estranhamento-de-si (Selbstentfremdung), tal qual acima o estranhamento da coisa (MARX, 2008, p. 83, destaque do autor).

Segundo Marx, o trabalhador sofre com o poder que os produtos criados por seu trabalho exercem sobre ele próprio, gerando um estranhamento. $\mathrm{Na}$ verdade, existe esse processo de estranhamento porque o produto criado pelo trabalhador torna-se propriedade do outro e não dele. Neste sentido, o autor afirma: quanto mais o trabalhador cria um mundo de riqueza cristalizado nos objetos, mais pobre ele se torna. Desta maneira, para Marx,

Quanto mais o trabalhador se desgasta trabalhando (ausarbeitet), tanto mais poderoso se torna o mundo objetivo, alheio (fremd) que ele cria diante de si, tanto mais pobre se torna ele mesmo, seu mundo interior, 
[e] tanto menos [o trabalhador] pertence a si próprio (MARX, 2008, p. 81 , destaque do autor).

Marx (2013) mostra que tanto a mercadoria quanto o trabalho apresentam um duplo caráter que se revela no valor de uso e valor de troca. No que diz respeito ao trabalho concreto/útil, ele o define como aquele que cria valor de uso e exige aplicação da força física. Ou seja, é a materialização do trabalho, e tem uma relação qualitativa. É o trabalho vivo. Não se deve perder de vista que o trabalho concreto/útil está relacionado ao surgimento das necessidades e tem o objetivo de atendê-las.

Quanto ao trabalho abstrato, Marx (2013) revela que ele é imaterial, que cria valor de troca, está relacionado aos aspectos intangíveis que, normalmente, não são percebidos e dizem respeito aos aspectos quantitativos. O trabalho morto, por sua vez, refere-se ao tempo que o trabalhador leva na produção de uma mercadoria. Ele é produtor de mais valia. É o tempo de trabalho abstrato que determina o valor de troca de uma mercadoria. Pode-se entender melhor, com base nas palavras de Marx:

Todo trabalho é por um lado, dispêndio de força humana de trabalho em sentido fisiológico, e graças a essa sua propriedade de trabalho humano igual ou abstrato ele gera o valor das mercadorias. Por outro lado, é dispêndio de força humana de trabalho numa forma específica, determinada à realização de um fim, e, nessa qualidade de trabalho concreto e útil, ele produz valores de uso (MARX, 2013, p. 124).

Antunes corrobora o pensamento de Marx, quando afirma que

O trabalho, entendido no seu sentido mais genérico e abstrato como produtor de valores de uso, é expressão de uma relação metabólica entre o ser social e a natureza. No seu sentido primitivo e limitado, por meio do ato laborativo, objetos naturais são transformados em coisas úteis (ANTUNES, 2006, p. 139).

Nesse sentido, fica evidente que o trabalho revela seu duplo caráter na mercadoria. Marx (2013, p.123) aponta que a mercadoria tem duas grandezas de valor: uma acerca do valor de uso, que trata do "como" e do "que" do trabalho. E se refere ao valor de troca, fazendo alusão à quantidade de sua duração. Para melhor entendimento, o exemplo do próprio Marx pode ser utilizado, pois ele afirma que um casaco tem o dobro do valor de dez braças de linho. Ele explica que esta diferença provém de grandezas de valor e do fato de que o linho contém somente a metade do trabalho 
contido no casaco, pois, para a sua produção, o dispêndio da força de trabalho levou o dobro de tempo necessário para a sua confecção. Segundo Moreira:

Tal especificidade deriva do caráter duplo que o processo do trabalho adquire, o trabalho concreto e o trabalho abstrato, fruto do duplo caráter que aí também assume o valor, distinguido no valor de uso (o valor produzido pelo trabalho concreto) e no valor de troca (o valor produzido pelo trabalho abstrato). Caracteristicamente, assim, o trabalho existe de modo fragmentário, com o capital assumindo o lugar ontológico de significação e integralidade do todo (MOREIRA, 2013, p. 132).

Moreira (2013) relata que o começo da criação do trabalho abstrato foi a manufatura, pois ela se diferia do artesanato familiar e era uma atividade de produção exclusivamente industrial, além de apoiar-se na divisão técnica e na relação capitaltrabalho. A manufatura passou a concentrar a força de trabalho, o capital e a produção em um mesmo local. Moreira assevera:

Foi o começo da criação do trabalho abstrato, que, mais à frente, daria na constituição da sociedade do trabalho. A base desta criação foi a instituição da divisão interna e externa do trabalho pela manufatura, pondo o trabalho concreto, o trabalho produtor de valor de uso, a mover-se dentro do trabalho abstrato, o trabalho produtor de valor de troca, num combinado de trabalho coletivo (MOREIRA, 2012, p. $135)$.

Para Moreira (2013, p. 137), o tempo da manufatura já era o tempo cronométrico do relógio, do número fixo de horas de atividade dentro do prédio e da regularidade diária do exercício do trabalho. Desse modo, ele indica cinco fatos que considera os embriões da centralidade do trabalho abstrato:

- A cadeia integrada dos trabalhos concretos dos artesãos, articulados num só movimento produtivo.

- A concentração do circuito de compra e venda na esfera do mercado.

- A forma de excedente produzida.

- O valor realizado no movimento de compra e venda do produto.

- O movimento do capital-dinheiro investido num ciclo repetitivo de reprodutibilidade intensiva. 


\section{Considerações finais}

Enfim, abordar a definição de trabalho não é uma resolução fácil e objetiva, pois esse é um tema que apresenta variadas questões que carregam determinadas nuances de cada momento histórico. Trata-se de um assunto do âmbito não somente técnico, mas, sobretudo, social, que o torna amplo, rico e inesgotável. Um conteúdo que suscita curiosidades e leva à realização de conjecturas. Tudo isso o torna uma temática agradável de ser estudada.

\section{Referências}

ANTUNES, Ricardo. Os sentidos do trabalho. São Paulo: Boitempo, 2006.

FRANCESCONI, Léa. Trabalho, tema de pesquisa geográfica. São Paulo: FFLCH/USP, 2007.

GRINT, K. Sociologia do Trabalho. Lisboa: Instituto Piaget, 1998.

HARVEY, D. Para Entender o Capital. Livro 1. São Paulo: Boitempo, 2013.

HEGEL, G. W. F. Fenomenologia do Espírito (Tradução de Paulo Meneses), $5^{a}$ ed., Petrópolis: Editora Vozes, 2008

MARX, Karl. Manuscritos Econômico-Fiosóficos. Trad. Jesus Ranieri. São Paulo: Boitempo, 2008.

MARX, Karl. O Capital: Crítica da Economia Política. O Processo de Produção do Capital. Livro 1. Tradução de Rubens Enderle. São Paulo: Boitempo, 2013.

MOREIRA, Rui. As Três revoluções industriais. In GIL, Isabel C. Inovações tecnológicas neste final de século. Revista Ciência Geográfica. São Paulo. No 8/dezembro, 2012. Disponível em: www.agbbauru.org.br/.../revista/...versao.../Revista_AGB_JanDez2013. Acesso em: 04 de março de 2016.

MOREIRA, Ruy. A Geografia da sociedade do trabalho. Terra Livre. v.1, n. 40, p. 131-142, Jan/Jun, 2013. Disponível em: www.agbbauru.org.br/.../revista/...versao.../Revista_AGB JanDez2013. Acesso em: 10 de março 2016.

OLIVEIRA, V. F. A Reestruturação Produtiva do Capital e o Trabalho na Agroindústria Cafeeira de Barra do Choça -BA. 2009. 139 f. Dissertação (mestrado em Geografia). Universidade Federal de Sergipe: São Cristóvão, 2009.

SANTOS, Milton. A urbanização brasileira. $5^{\text {a }}$ ed. São Paulo: Editora da Universidade de São Paulo, 1980.

THOMAZ JÚNIOR, Antônio. O mundo do trabalho e as transformações territoriais: os limites da 'leitura' geográfica. Revista Pegada Eletrônica, Presidente Prudente, 2002. 
v. 3, n. 1. Disponível: revista.fct.unesp.br/index.php/pegada/article/viewF ile/1700/1633 Acesso em: 15 de março de 2016.

THOMAZ JÚNIOR, Antônio. Leitura geográfica da práxis social do trabalho. Abalar. Santiago de Compostela, 2005. n. 5. Disponível:www.ub.edu/geocrit/9porto/thomaz. htmwww.ub.edu/geocrit/9porto/thomaz.htmwww.ub.edu/geocrit/9porto/thomaz.htm. Acesso em: 24 mar. 2106.

VATIN, François. Epistemologia e Sociologia do trabalho. Lisboa: Instituto Piaget, 1999. 